\title{
Spinal Surgeons' Opinions on Pre- and Postoperative Rehabilitation in Patients Undergoing Lumbar Spinal Fusion Surgery
}

Citation for published version (APA):

Van Erp, R. M. A., Jelsma, J., Huijnen, I. P. J., Lundberg, M., Willems, P. C., \& Smeets, R. J. E. M. (2018). Spinal Surgeons' Opinions on Pre- and Postoperative Rehabilitation in Patients Undergoing Lumbar Spinal Fusion Surgery: A Survey-Based Study in the Netherlands and Sweden. Spine, 43(10), 713-719. https://doi.org/10.1097/BRS.0000000000002406

Document status and date:

Published: 15/05/2018

DOI:

10.1097/BRS.0000000000002406

Document Version:

Publisher's PDF, also known as Version of record

\section{Document license:}

Taverne

Please check the document version of this publication:

- A submitted manuscript is the version of the article upon submission and before peer-review. There can be important differences between the submitted version and the official published version of record.

People interested in the research are advised to contact the author for the final version of the publication, or visit the DOI to the publisher's website.

- The final author version and the galley proof are versions of the publication after peer review.

- The final published version features the final layout of the paper including the volume, issue and page numbers.

Link to publication

\footnotetext{
General rights rights.

- You may freely distribute the URL identifying the publication in the public portal. please follow below link for the End User Agreement:

www.umlib.nl/taverne-license

Take down policy

If you believe that this document breaches copyright please contact us at:

repository@maastrichtuniversity.nl

providing details and we will investigate your claim.
}

Copyright and moral rights for the publications made accessible in the public portal are retained by the authors and/or other copyright owners and it is a condition of accessing publications that users recognise and abide by the legal requirements associated with these

- Users may download and print one copy of any publication from the public portal for the purpose of private study or research.

- You may not further distribute the material or use it for any profit-making activity or commercial gain

If the publication is distributed under the terms of Article $25 \mathrm{fa}$ of the Dutch Copyright Act, indicated by the "Taverne" license above, 


\title{
Spinal Surgeons' Opinions on Pre- and Postoperative Rehabilitation in Patients Undergoing Lumbar Spinal Fusion Surgery
}

\author{
A Survey-Based Study in the Netherlands and Sweden \\ Reni M.A. van Erp, MSc, ${ }^{*}$ Jetse Jelsma, MSc, ${ }^{\dagger}$ Ivan P.J. Huijnen, $\mathrm{PhD},{ }^{*, \ddagger}$ Mari Lundberg, $\mathrm{PhD}, \$, q$ \\ Paul C. Willems, PhD, " and Rob. J.E.M. Smeets, PhD ${ }^{*, * *}$
}

Study Design. A cross-sectional survey in the Netherlands and Sweden.

Objective. To investigate Dutch and Swedish spinal surgeons' opinions on spinal fusion pre- and postoperative rehabilitation.

Summary of Background Data. Lumbar spinal fusion surgery is increasingly provided in patients with chronic low back pain. No guidelines however exist for pre- and postoperative rehabilitation and it is unknown what opinions spinal surgeons currently have about pre- and postoperative rehabilitation.

Methods. A survey was circulated to Dutch and Swedish spinal surgeons. Reminders were sent after 4 and 8/9 weeks. Data of completed questionnaires of orthopedic- and neurosurgeons currently performing lumbar spinal fusion were included for analysis. Analysis comprised a range of descriptive summaries (numerical, graphical, and tabular).

Results. Surveys of 34 Dutch and 48 Swedish surgeons were analyzed. Surgeons provided preoperative information on postoperative mobilization. Spinal fusion techniques varied, but technique did not influence postoperative treatment. Swedish

From the *Department of Rehabilitation Medicine, CAPHRI, Maastricht University, Maastricht, The Netherlands; 'Department of Orthopedics, Zuyderland Medisch Centrum, Heerlen, The Netherlands; ${ }^{\ddagger}$ Adelante, Centre of Expertise in Rehabilitation and Audiology, Hoensbroek, The

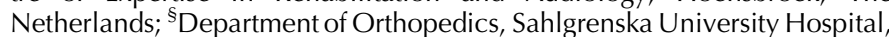
Gothenburg, Sweden; "Division of Physiotherapy, Department of Neurobiology, Care Sciences and Society (NVS), Karolinska Institutet, Huddinge, Sweden; "Department of Orthopedics, Maastricht University Medical Centre, Maastricht, The Netherlands; and **Libra Rehabilitation and Audiology Location Blixembosch, SJG, Weert, The Netherlands.

Acknowledgment date: May 4, 2017. First revision date: July 17, 2017. Acceptance date: August 10, 2017.

The manuscript submitted does not contain information about medical device(s)/drug(s).

No funds were received in support of this work.

No relevant financial activities outside the submitted work.

Address correspondence and reprint requests to Reni M.A. van Erp, MSc, Department of Rehabilitation Medicine, CAPHRI, Maastricht University, Universiteitssingel 40, P.O. Box 616, 6200 MD, Maastricht, The Netherlands; E-mail: reni.vanerp@maastrichtuniversity.nl

DOI: 10.1097/BRS.0000000000002406 surgeons recommended slightly faster mobilization than Dutch (direct vs. 1-day postoperative), and more activities the first day (sitting, standing, walking). Stair climbing was the most reported discharge criterion; however, time point to start varied. More Swedish surgeons referred to postoperative physiotherapy than Dutch (88\% vs. 44\%). Time-point to start home activities varied from 1 week to more than 6 months. Pain increase was allowed for less than 24 hours (The Netherlands 81\%, Sweden 92\%).

Conclusion. Findings reflect variability in lumbar spinal fusion rehabilitation in two European countries, especially in postoperative phase. The study proposes many new research topics and acts as starting point for future research valuable for the spinal community.

Key words: chronic low back pain, fusion, international survey, low back pain, lumbar spinal fusion, physiotherapy, rehabilitation, spinal surgery, surgeon opinions, surgeon practice.

Level of Evidence: 3

Spine 2018;43:713-719

$\mathrm{n}$ patients with low back pain, initial management includes advice to stay active and/or conservative treatment. ${ }^{1}$ When conservative treatments do not suffice and symptoms can be (partially) attributed to specific pathology (e.g., spinal stenosis, spondylolisthesis, or degenerative disc disease [DDD]), invasive treatments such as injections or surgical interventions are potential alternatives. ${ }^{2,3}$ Spinal fusion is one such surgical intervention that is commonly performed. Although its effectiveness and success rate has been criticized as conservative treatments (with lower burden) show equal outcomes, ${ }^{4}$ the incidence of lumbar spinal fusion is large and has increased worldwide. ${ }^{3,5,6}$ In the United States, for example, the overall annual number of spinal fusion surgeries increased from 174,223 to 413,171 between 1998 and 2008. ${ }^{5}$ In Sweden, spinal fusion is also the most commonly performed surgery for spondylolisthesis and DDD. ${ }^{3}$ 
The major goal of fusion surgery is to reduce pain, increase function, and health-related quality of life. It has been demonstrated that preoperative fitness improves surgical outcome postoperatively. ${ }^{7}$ Hence, prehabilitation (i.e., preliminary rehabilitation before surgery) has become a growing field in spinal surgery. ${ }^{8-10}$ Evidence-based guidelines for prehabilitation, however, do not exist. Similar is true for postoperative rehabilitation. As a consequence, variability in practice is seen between spinal surgeons at pre- and postoperative phase (i.e., variability in discharge criteria, outcome measures, hospital stay, follow-up frequency, and intensity). ${ }^{11}$ Also from clinical experience we notice uncertainty among health care specialists about appropriate advice for mobilization, loading, functional activities, or rehabilitation after spinal fusion. It is possible that this fuels uncertainty in some patients, leading to fear of movement and increased disability.

Since there is uncertainty and variability in practice, it is important to investigate what kind of opinions spinal surgeons have about pre- and postoperative rehabilitation. Improving understanding about current opinions is valuable when developing consensus guidelines and to stimulate clinical trials to evaluate different strategies. To our knowledge, no study has yet been performed to investigate spinal surgeons' opinions in the Netherlands and Sweden. The purpose of the present study was to create an inventory of the opinions of Dutch and Swedish spinal surgeons regarding pre-and postoperative rehabilitation for patients with lumbar DDD who undergo spinal fusion.

\section{MATERIALS AND METHODS}

\section{Design and Population}

A cross-sectional survey was conducted among Dutch and Swedish spinal surgeons. The Dutch Medical Ethics Approval Committee approved the Dutch survey (METC 14-5-035). According to the Swedish Law, this study did not fall under the Act (2003:460) concerning the Ethical Review of Research Involving Humans. The study is reported according to the Strengthening the Reporting of Observational Studies in Epidemiology statement. ${ }^{12}$

Recruitment was conducted via the Dutch Spine Society (DSS) and Swedish Society of Spinal Surgeons (4S). Members of the DSS and S4 were sent an invitation letter for participation and a link to an online survey distributed by MEMIC (Center for Data and Information Management, The Netherlands; 11/2014-01/2015) or Webropol online survey tool (Sweden; 05/2015-09/2015). By returning the questionnaire, surgeons gave written consent for participation. Reminders were sent out after 4 and 8 weeks (The Netherlands), and 4 and 9 weeks (Sweden).

\section{Survey}

The survey was developed by a multiprofessional team: a spinal surgeon (PW), a consultant in rehabilitation medicine (RS), a physiotherapist (ML), and a resident in rehabilitation medicine and orthopedics (JJ). Questions were originally formulated in English and sent to Dutch spinal surgeons. The survey consisted mainly of closed questions, subdivided into five parts: general information, preoperative phase, operative phase, postoperative phase, and follow-up (outpatient) phase. The English questionnaire was translated into Swedish and sent to Swedish spinal surgeons. Some answering options were slightly adapted based on recommendations from the $4 S$ (Appendix 1, http://links. lww.com/BRS/B300).

\section{Data Collection}

MEMIC (The Netherlands) and Webropol (Sweden) distributed the survey, collected data, and provided Dutch and Swedish researchers with completed data. Researchers in both countries were responsible for data cleaning their respective surveys. An independent Swedish researcher merged the datasets.

\section{Data Analysis}

Data analysis was performed in the Netherlands using IBM SPSS Statistics 22. Only data from orthopedic surgeons and neurosurgeons currently performing lumbar spinal fusion were included for analysis. Incomplete questionnaires and data of retired surgeons or surgeons working in countries other than the Netherlands or Sweden were excluded. Analysis comprised a range of descriptive summaries (numerical, graphical, and tabular).

\section{RESULTS}

Forty of the 105 Dutch spinal surgeons returned the questionnaire (response rate 38\%; Figure 1). Six provided incomplete data, resulting in 34 surveys analyzed. In Sweden, 48 of the 140 spinal surgeons returned the questionnaire (response rate 34\%). All were included for analysis.

\section{Characteristics of Spinal Surgeons}

Most spinal surgeons worked as orthopedic surgeons (The Netherlands $71 \%$, Sweden 94\%; Table 1). Approximately half of all Dutch spinal surgeons and three quarter of all Swedish spinal surgeons had experience for more than 10 years. The number of spinal fusions performed per year varied considerably in both countries. Years of experience and number of fusions per year did not influence pre- and postoperative treatment.

\section{Preoperative Phase}

Most Dutch and Swedish spinal surgeons provided preoperative information on postoperative mobilization (The Netherlands 97\%, Sweden 98\%). Preoperative information was mainly provided by surgeons themselves (The Netherlands 100\%, Sweden 96\%). Other less frequently reported pathways were by nurse (The Netherlands $38 \%$, Sweden 23\%), letter (The Netherlands 44\%, Sweden 19\%), physiotherapist (The Netherlands 9\%, Sweden 54\%), brochure (The Netherlands $12 \%$, Sweden $10 \%$ ), Web site (The Netherlands 6\%), and/or occupational therapist (Sweden 


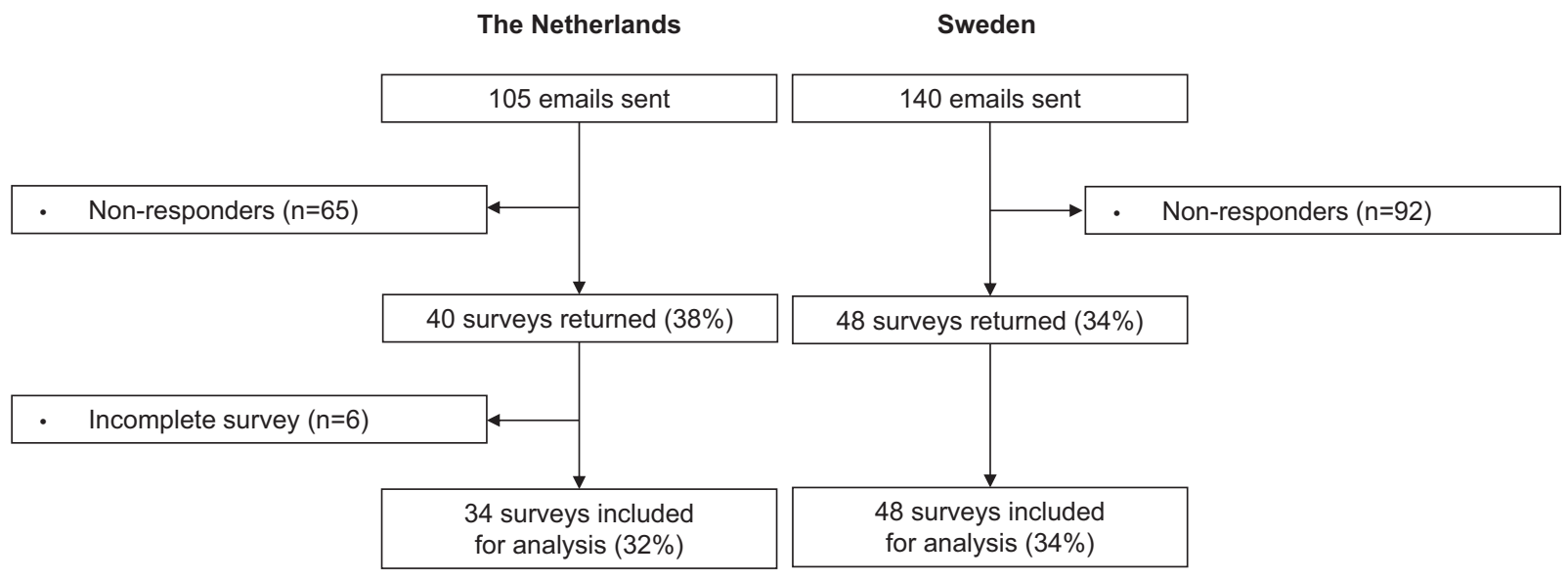

Figure 1. Flowchart of responders.

$4 \%)$. Referral to preoperative physiotherapy varied, but was recommended by (almost) one-third of the Dutch $(27 \%)$ and Swedish surgeons $(35 \%)$. Other surgeons referred only rarely/sometimes (The Netherlands 35\%, Sweden 46\%) or not at all (The Netherlands 38\%, Sweden 19\%).

\section{Operative Phase}

Both countries used multiple spinal fusion techniques, but most Dutch $(91 \%)$ and almost three quarter of the Swedish spinal surgeons $(73 \%)$ reported that the technique, regardless of their preference, did not influence postoperative treatment.

\section{Postoperative Phase}

The majority of the Dutch spinal surgeons recommended mobilization the first day postoperative $(63 \%)$, whereas most Swedish spinal surgeons recommended mobilization directly $(73 \%$; Figure 2$)$.

Almost all Dutch and Swedish spinal surgeons advised mobilization to be guided by a physiotherapist (The Netherlands $97 \%$, Sweden $100 \%$ ). At the first day postoperatively, the majority of the Dutch and Swedish spinal surgeons recommended sitting in bed $188 \%$ and $98 \%$;
Figure 3), while most Swedish spinal surgeons also advised standing $(98 \%)$, and walking with support $(85 \%)$. The ability to climb stairs was the most reported physical discharge criterion (The Netherlands 74\%, Sweden 56\%).

Most Dutch and Swedish spinal surgeons recommended supervision while start standing (94\% vs. $85 \%)$, walking with support $(97 \%$ vs. $88 \%)$, walking without support ( $86 \%$ vs. $92 \%$ ), and stair climbing (100\% vs. $98 \%$ ). Dutch spinal surgeons also recommended supervision while start sitting in bed $(76 \%)$.

Almost all Dutch and Swedish spinal surgeons agreed that pain after mobilization was permitted (The Netherlands $94 \%$, Sweden $98 \%$ ). Approximately one-third of the Dutch $(28 \%)$ and two-third of the Swedish spinal surgeons $(66 \%)$ reported that this pain was permitted for maximally 6 hours. Half $(53 \%)$ of the Dutch, and $26 \%$ of the Swedish spinal surgeons permitted increased pain until 24 hours. Remaining surgeons permitted pain more than 24 hours.

\section{Postoperative Outpatient Phase}

Almost all Dutch and Swedish spinal surgeons advised walking and stair climbing in the first week (Tables 2 and $3)$. There was no consensus on when to return to other

\section{TABLE 1. Characteristics of Dutch Responders $(n=34)$ and Swedish Responders $(n=48)$}

\begin{tabular}{|c|c|c|c|c|c|}
\hline & \multicolumn{2}{|c|}{ The Netherlands } & \multicolumn{3}{|c|}{ Sweden } \\
\hline & $\begin{array}{c}\text { Orthopedic Surgeons } \\
\text { n (\%) }\end{array}$ & $\begin{array}{c}\text { Neurosurgeons } \\
\text { n (\%) }\end{array}$ & $\begin{array}{c}\text { Orthopedic Surgeons } \\
\text { n ( } \%)\end{array}$ & $\begin{array}{c}\text { Neurosurgeons } \\
\text { n (\%) }\end{array}$ & $\begin{array}{l}\text { Both } \\
\text { n (\%) }\end{array}$ \\
\hline No. responders & 24 & 10 & 45 & 2 & 1 \\
\hline \multicolumn{6}{|c|}{ Clinical experience } \\
\hline$<5 \mathrm{yr}$ & $6(25)$ & $0(0)$ & $3(7)$ & $0(0)$ & $0(0)$ \\
\hline $5-10 \mathrm{yr}$ & $6(25)$ & $4(40)$ & $8(18)$ & $0(0)$ & $0(0)$ \\
\hline$>10 \mathrm{yr}$ & $12(50)$ & $6(60)$ & $34(76)$ & $2(100)$ & $1(100)$ \\
\hline \multicolumn{6}{|c|}{ No. fusions per year } \\
\hline $1-25$ & $12(50)$ & $1(10)$ & $20(44)$ & $0(0)$ & $0(0)$ \\
\hline $26-50$ & $2(8)$ & $3(30)$ & $14(31)$ & $0(0)$ & $0(0)$ \\
\hline $51-75$ & $7(29)$ & $3(30)$ & $7(16)$ & $0(0)$ & $0(0)$ \\
\hline $76-100$ & $2(8)$ & $1(10)$ & $2(4)$ & $1(50)$ & $0(0)$ \\
\hline$>100$ & $1(4)$ & $2(20)$ & $2(4)$ & $1(50)$ & $1(100)$ \\
\hline
\end{tabular}




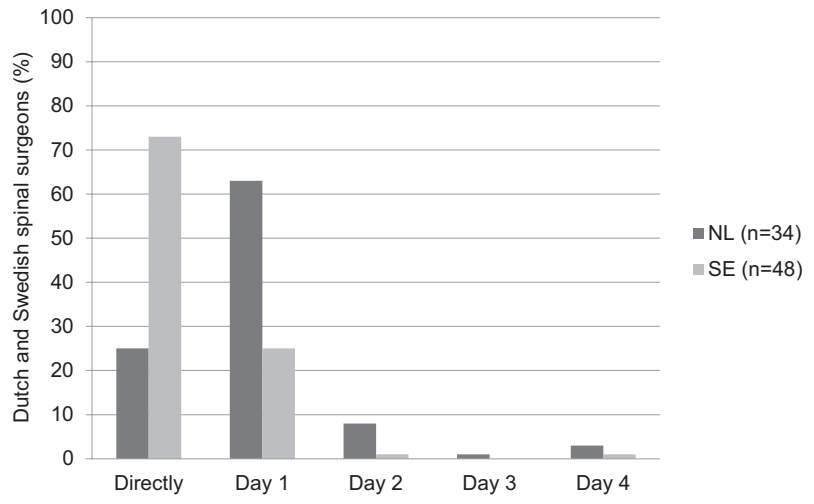

Figure 2. Time points at which patients can be mobilized after lumbar spinal fusion surgery.

activities as advice varied considerably from the first day postoperatively to more than 6 months. A few surgeons discouraged running, rotating, extending, and jumping.

Advice on maximum lifting weight and jumping height varied in both countries from less than $5 \mathrm{~kg}$ or less than $5 \mathrm{~cm}$ to no limit at all (Figures 4 and 5). Additional Swedish recommendations for lifting included patient-dependent, not applicable if proper lifting techniques are used, and allowed until patient's pain threshold. For jumping, one additional recommendation was reported, patient's choice. Five Swedish spinal surgeons had no opinion and 13 did not report maximum lifting weight.

More than two-third of the Dutch and Swedish spinal surgeons advised against wearing a corset $(68 \%$ and $69 \%)$. The small group recommending a corset, showed large variation in wearing advice (e.g., until 6 weeks, until 3 months, patient's choice, during lifting, or physical activities).

Fewer Dutch (44\%) than Swedish spinal surgeons (88\%) referred to postoperative physiotherapy.

Spinal surgeons who did prescribe physiotherapy varied in advice when to start physiotherapy; ranging from immediately to 9 to 12 weeks. Top three treatments that should not be provided were (1) manual therapy (The Netherlands $82 \%$,

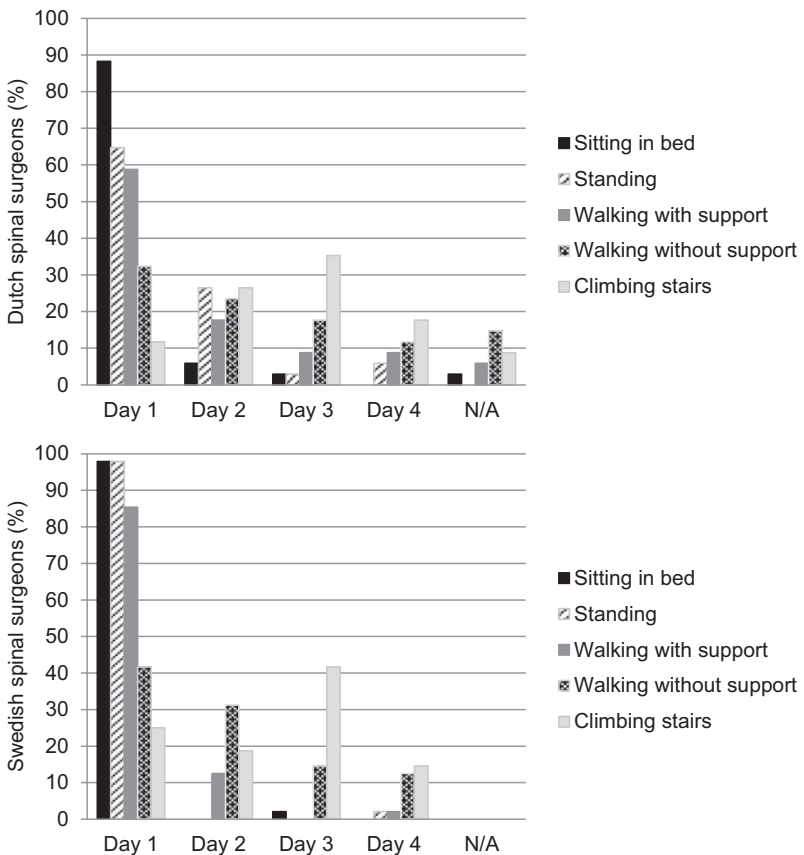

Figure 3. Time points at which functional activities can be performed postoperatively as reported by Dutch (above; $n=34$ ) and Swedish (below; $\mathrm{n}=48$ ) spinal surgeons.

Sweden 58\%), (2) mechanical diagnosis therapy (McKenzie; The Netherlands $35 \%$, Sweden $52 \%$ ), and (3) sensory stimulation (massage) (The Netherlands 32\%, Sweden 38\%). Of the Swedish spinal surgeons, $27 \%$ had no opinion. Also one Dutch spinal surgeon reported to have no idea.

Advice for return to work was most commonly reported to be dependent on type of work. Other less frequently reported approaches were a pain-contingent increase and time-contingent increase in working hours. One Dutch and one Swedish spinal surgeon had no opinion. Other factors reported by Swedish surgeons were "based on duration of disorder," "psychological well-being," "radiologic healing," "whether occupation can be adapted to a high degree," and "never before 3 months."

\begin{tabular}{|c|c|c|c|c|c|c|c|}
\hline & \multicolumn{7}{|c|}{$\begin{array}{l}\text { The Netherlands } \\
\text { No. Surgeons (\%) }\end{array}$} \\
\hline & 1-7 Days & 1-4 wk & $5-8$ wk & 9-12 wk & $3-6 \mathrm{mo}$ & $>6 \mathrm{mo}$ & Never \\
\hline Walking & $34(100)$ & 0 & 0 & 0 & 0 & 0 & 0 \\
\hline Stair climbing & $31(91)$ & $2(6)$ & $1(3)$ & 0 & 0 & 0 & 0 \\
\hline Running & $2(6)$ & $2(6)$ & $6(18)$ & $3(9)$ & $14(41)$ & $6(18)$ & $1(3)$ \\
\hline Bending forward & $6(18)$ & $4(12)$ & $10(29)$ & $4(12)$ & $10(29)$ & 0 & 0 \\
\hline Rotation to end position & $6(18)$ & $3(9)$ & $6(18)$ & $8(24)$ & $11(32)$ & 0 & 0 \\
\hline Extension to end position & $6(18)$ & $2(6)$ & $7(21)$ & $9(26)$ & $10(29)$ & 0 & 0 \\
\hline Cycling & $2(6)$ & $3(9)$ & $18(53)$ & $3(9)$ & $7(21)$ & $1(3)$ & 0 \\
\hline Driving car & $2(6)$ & $7(21)$ & $20(59)$ & $3(9)$ & $2(6)$ & 0 & 0 \\
\hline Swimming (breaststroke) & $1(3)$ & $3(9)$ & $12(35)$ & $7(21)$ & $10(29)$ & $1(3)$ & 0 \\
\hline Lifting $(2.5 \mathrm{~kg})$ & $3(9)$ & $2(6)$ & $9(26)$ & $6(18)$ & $9(26)$ & $5(15)$ & 0 \\
\hline Jumping $(10 \mathrm{~cm})$ & $2(6)$ & 0 & $5(15)$ & $5(15)$ & $15(44)$ & $6(18)$ & $1(3)$ \\
\hline
\end{tabular}




\begin{tabular}{|c|c|c|c|c|c|c|c|}
\hline & \multicolumn{7}{|c|}{$\begin{array}{c}\text { Sweden } \\
\text { No. Surgeons (\%) }\end{array}$} \\
\hline & 1-7 Days & 1-4 wk & 4-8 wk & 8-12 wk & $3-6 \mathrm{mo}$ & $>6 \mathrm{mo}$ & Never \\
\hline Walking & $48(100)$ & 0 & 0 & 0 & 0 & 0 & 0 \\
\hline Stair climbing & $46(96)$ & $2(4)$ & 0 & 0 & 0 & 0 & 0 \\
\hline Running & $2(4)$ & $3(6)$ & $10(21)$ & $8(17)$ & $19(40)$ & $4(8)$ & $2(4)$ \\
\hline Bending forward & $17(35)$ & $13(27)$ & $8(17)$ & $4(8)$ & $6(13)$ & 0 & 0 \\
\hline Rotation to end position & $12(25)$ & $12(25)$ & $6(13)$ & $4(8)$ & $10(21)$ & $2(4)$ & $2(4)$ \\
\hline Extension to end position & $15(31)$ & $10(21)$ & $8(17)$ & $5(10)$ & $7(15)$ & $1(2)$ & $2(4)$ \\
\hline Cycling & $3(6)$ & $14(29)$ & $11(23)$ & $8(17)$ & $10(21)$ & $2(4)$ & 0 \\
\hline Driving car & $2(4)$ & $18(38)$ & $12(25)$ & $12(25)$ & $3(6)$ & $1(2)$ & 0 \\
\hline Swimming (breaststroke) & $2(4)$ & $7(15)$ & $19(40)$ & $8(17)$ & $10(21)$ & $2(4)$ & 0 \\
\hline Lifting $(2.5 \mathrm{~kg})$ & $7(15)$ & $7(15)$ & $12(25)$ & $7(15)$ & $11(23)$ & $4(8)$ & 0 \\
\hline Jumping $(10 \mathrm{~cm})$ & $2(4)$ & $5(10)$ & $6(13)$ & $9(19)$ & $18(38)$ & $5(10)$ & $3(6)$ \\
\hline
\end{tabular}

\section{DISCUSSION}

This study provides an overview of opinions of Dutch and Swedish spinal surgeons about current pre- and postoperative rehabilitation in patients undergoing lumbar spinal fusion. One interesting findings was that nearly all surgeons provided preoperative information on postoperative mobilization. This is comparable to British spinal surgeons of whom $91 \%$ provided preoperative information. ${ }^{11}$ In the Netherlands, additional preoperative information was most frequently provided by a letter and/or nurse, whereas in Sweden this was done by a physiotherapist. Although different professionals were involved, findings indicate consensus on providing preoperative information. Further studies are required to investigate what the content of information should be, who should deliver it and at what time point.

Consensus on preoperative information links nicely with the growing evidence for prehabilitation. ${ }^{7,13,14}$ Recent literature supports referral to prehabilitation programs as it facilitates mobilization and lowers the length of hospital stay as compared to standard care. ${ }^{8}$ Moreover, if cognitive behavioral elements are added, patients show a lower intake of analgesics. ${ }^{9}$ Referral to prehabilitation was however not

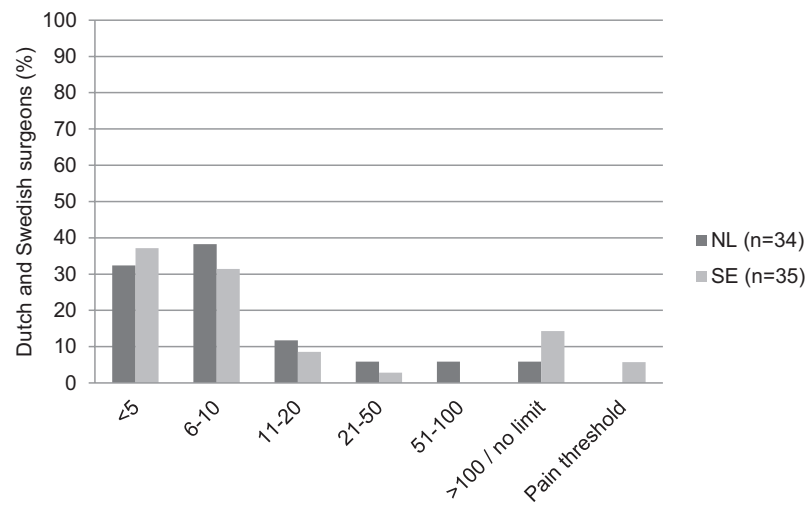

Figure 4. Maximum lifting weight $(\mathrm{kg})$ as advised by Dutch and Swedish spinal surgeons.

Spine consistently recommended in both countries. One possible explanation is that prehabilitation is still in its infancy, not well known by spinal surgeons, and not structurally implemented in clinical practice.

Swedish spinal surgeons recommended slightly faster postoperative mobilization in the hospital than Dutch spinal surgeons, but overall, both countries mobilized patients within 1 day. This corresponds with current physiotherapy practice in the UK where most patients were seen within the first day postoperatively. ${ }^{15}$ Swedish spinal surgeons started activities such as standing and walking slightly earlier than Dutch spinal surgeons. This might presume faster discharge and therefore shorter duration of hospital stay in Sweden, although this assumption could not be checked with this study. This study identified that both countries used the same physical discharge criteria (i.e., the ability to climb stairs independently). The time point to start this activity varied in both countries from day 1 to 4 . It is therefore possible that the duration of hospital stay varies within each country. It is recommended to find consensus on the time point to start such functional activities as it will likely improve uniformity on discharge and shorten hospital stay.

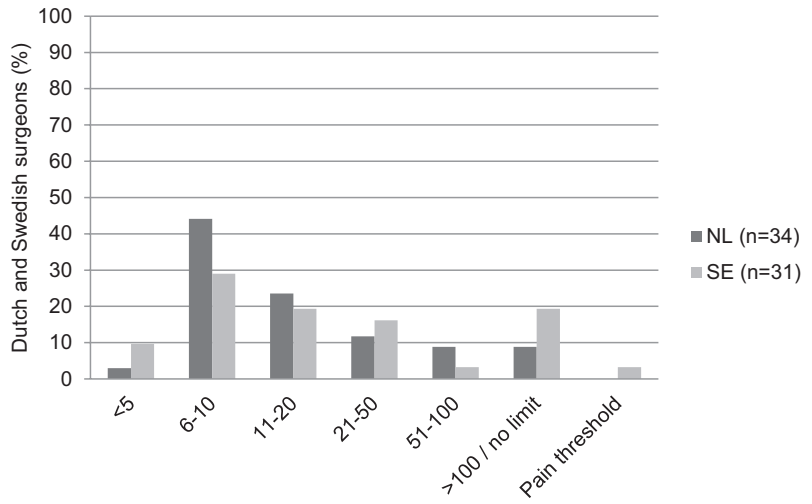

Figure 5. Maximum jumping height (centimeters) as advised by Dutch and Swedish spinal surgeons.

www.spinejournal.com 
In our study, few surgeons advised never to jump or run again, whereas others advised to jump or run in the first week. Furthermore, some surgeons allowed maximally $5 \mathrm{~cm}$ for jumping, or $5 \mathrm{~kg}$ for lifting, whereas others reported no limits at all. It seems that surgeons have varying ideas about the time point to start these activities and its intensity, or as few surgeons in our study reported, have no opinion at all. Variability in advice corresponds with Rushton et $\mathrm{ll}^{11}$ where recommendations for activities such as jogging, sports, and lifting ranged from 2 weeks to 9 months. The finding that surgeons working in different European countries provide different advice, suggests the need for clinical guidance.

Another important finding was that pain is permitted as part of the rehabilitation process, although it seemed hard to define at what time point the mobilization strategy should be adjusted. The majority allowed an increase of pain for less than 24 hours. Of note is that more than half of the Swedish surgeons allowed pain for less than 6 hours. Further studies could investigate whether increased pain symptoms after activities should be used to modify rehabilitation.

The final major finding was the lack of consensus regarding postoperative referral to physiotherapy (except from Swedish surgeons), the time point to start postoperative physiotherapy, as well as the type of therapy. Postoperative physiotherapy seems beneficial for recovery, ${ }^{16}$ but currently little evidence is available for optimal timing and specific treatment elements. Oestergaard et al, ${ }^{17,18}$ for example, found that initiation of rehabilitation at 6 weeks was less effective and more expensive than initiation of rehabilitation at 12 weeks. In addition, they reported that adding cognitive behavioral elements could increase the overall effectiveness. Abbot et al ${ }^{19}$ provided early rehabilitation with cognitive behavioral elements (within the first 3 months) and showed significant larger improvements in functional disability, self-efficacy, outcome expectancy, and fear of movement/(re)injury than exercise therapy alone. This study highlights the potential role of cognitive behavioral elements and early postoperative rehabilitation.

The study included data of both Dutch and Swedish spinal surgeons and therefore provided an overview of surgeons' practice in two European countries. The number of surgeons analyzed is comparable to other recently conducted cross-sectional studies. ${ }^{11,20}$ We discovered consistent opinions valuable for consensus guidelines, as well as inconsistent opinions and variability in practice leading to new research topics. We believe this study can act as a starting point for future research and will be valuable for the spinal community.

One limitation of the study is the relatively low response rate $(38 \%$ and $34 \%)$ which increases the risk for bias. It is possible that surgeons with more interest in rehabilitation were more likely to complete the survey than surgeons with less interest. Consequently, opinions might have been different between responders and nonresponders and therefore not entirely reflect clinical practice.

There are methodological and process challenges associated with conducting a study across two countries. Multiple ethical committees and advisory boards must be considered with cultural variance and recommendations. One example for this study is the recommendation of the $4 S$ to slightly adapt the Swedish survey. Eventually these adjustments have not influenced our results since our aim was to describe the findings narratively.

It is recommended for future studies to systematically translate the survey and to keep questions and answering options standardized. Transparency, communication, structured management, and documentation are key characteristics. It is recommended to adopt a study protocol and to appoint a project leader to systematically conduct an international study. For surgeons performing lumbar spinal fusion surgery it is desirable to provide clear and consistent instructions about the intensity and frequency of daily life activities (e.g., stair climbing, running, and lifting), as well as the time point to start. Future trials are needed to investigate the time point to start pre- and postrehabilitation, which health care professionals should be involved and what therapy elements are required for optimal recovery.

In summary, the findings of this study suggest variability in lumbar spinal fusion rehabilitation opinions in two European countries, especially in the postoperative phase. It seems unclear which activities are allowed, at what time point, and under what circumstances. Furthermore, physiotherapy (pre- and postoperative) seems to be less integrated in the rehabilitation process yet, although supported by literature. Future studies are needed to find consensus on suggested topics and to evaluate the effectiveness of treatment approaches to improve pre- and postoperative rehabilitation for patients undergoing spinal fusion.

\section{Key Points}

In total, 34 Dutch and 48 Swedish spinal surgeons completed an electronic survey on pre- and postoperative lumbar spinal fusion rehabilitation.

$\square$ There was considerable variability in opinions between spinal surgeons within two countries as well as between two countries.

$\square$ Variability in opinions was especially detected regarding postoperative rehabilitation (i.e., which activities/sports/work/therapies are allowed, at what time point, and to what intensity).

\section{Acknowledgments}

We acknowledge the members of the DSS and the Swedish Society of Spinal Surgeons for their participation in this study. Furthermore, we would like to thank Max Jakobsson for his contribution to the merging of data and Ken Stewart for editing the manuscript.

Supplemental digital content is available for this article. Direct URL citations appearing in the printed text are provided in the HTML and PDF version of this article on the journal's Web site (www.spinejournal.com). 


\section{References}

1. Koes BW, Van Tulder M, Lin CW, et al. An updated overview of clinical guidelines for the management of non-specific low back pain in primary care. Eur Spine J 2010;19:2075-94.

2. Jacobs WC, Rubinstein SM, Koes B, et al. Evidence for surgery in degenerative lumbar spine disorders. Best Pract Res Clin Rheumatol 2013;27:673-84.

3. Stromqvist B, Fritzell P, Hagg O, et al. Swespine: the Swedish spine register: the 2012 report. Eur Spine J 2013;22:953-74.

4. Brox JI, Nygaard OP, Holm I, et al. Four-year follow-up of surgical versus non-surgical therapy for chronic low back pain. Ann Rheum Dis 2010;69:1643-8.

5. Rajaee SS, Bae HW, Kanim LE, et al. Spinal fusion in the United States: analysis of trends from 1998 to 2008. Spine (Phila Pa 1976) 2012;37:67-76.

6. Du Bois M, Szpalski M, Donceel P. A decade's experience in lumbar spine surgery in Belgium: sickness fund beneficiaries, 2000-2009. Eur Spine J 2012;21:2693-703.

7. Snowden CP, Prentis J, Jacques B, et al. Cardiorespiratory fitness predicts mortality and hospital length of stay after major elective surgery in older people. Ann Surg 2013;257: 999-1004.

8. Nielsen PR, Jorgensen LD, Dahl B, et al. Prehabilitation and early rehabilitation after spinal surgery: randomized clinical trial. Clin Rehabil 2010;24:137-48.

9. Rolving N, Nielsen CV, Christensen FB, et al. Preoperative cognitive-behavioural intervention improves in-hospital mobilisation and analgesic use for lumbar spinal fusion patients. BMC Musculoskelet Disord 2016;17:217.

10. Lotzke H, Jakobsson M, Brisby H, et al. Use of the PREPARE (PREhabilitation, Physical Activity and exeRcisE) program to improve outcomes after lumbar fusion surgery for severe low back pain: a study protocol of a person-centred randomised controlled trial. BMC Musculoskelet Disord 2016;17:349.
11. Rushton A, White L, Heap A, et al. Evaluation of current surgeon practice for patients undergoing lumbar spinal fusion surgery in the United Kingdom. World J Orthop 2015;6:483-90.

12. Von Elm E, Altman DG, Egger M, et al. The Strengthening the Reporting of Observational Studies in Epidemiology (STROBE) statement: guidelines for reporting observational studies. Lancet 2007;370:1453-7.

13. Santa Mina D, Clarke H, Ritvo P, et al. Effect of total-body prehabilitation on postoperative outcomes: a systematic review and meta-analysis. Physiotherapy 2014;100:196-207.

14. Minnella EM, Bousquet-Dion G, Awasthi R, et al. Multimodal prehabilitation improves functional capacity before and after colorectal surgery for cancer: a five-year research experience. Acta Oncol 2017;56:295-300.

15. Rushton A, Wright C, Heap A, et al. Survey of current physiotherapy practice for patients undergoing lumbar spinal fusion in the United Kingdom. Spine (Phila Pa 1976) 2014;39:E1380-7.

16. McGregor AH, Probyn K, Cro S, et al. Rehabilitation following surgery for lumbar spinal stenosis. A Cochrane review. Spine (Phila Pa 1976) 2014;39:1044-54.

17. Oestergaard LG, Nielsen CV, Bunger CE, et al. The effect of early initiation of rehabilitation after lumbar spinal fusion: a randomized clinical study. Spine (Phila Pa 1976) 2012;37:1803-9.

18. Oestergaard LG, Christensen FB, Nielsen CV, et al. Early versus late initiation of rehabilitation after lumbar spinal fusion: economic evaluation alongside a randomized controlled trial. Spine (Phila Pa 1976) 2013;38:1979-85.

19. Abbott AD, Tyni-Lenne R, Hedlund R. Early rehabilitation targeting cognition, behavior, and motor function after lumbar fusion: a randomized controlled trial. Spine (Phila Pa 1976) 2010;35: 848-57.

20. Janssen ER, Scheijen EE, Van Meeteren NL, et al. Determining clinical practice of expert physiotherapy for patients undergoing lumbar spinal fusion: a cross-sectional survey study. Eur Spine J 2016;25:1533-41. 